


\title{
NOTAS SOBRE LAS CONSTRUCCIONES CONCESIVAS EN ESPAÑOL
}

\author{
REMARKS ON CONCESSIVE CONSTRUCTIONS \\ IN SPANISH LANGUAGE
}

Daniela Soledad Gonzalez

\begin{abstract}
RESUMEN
Este artículo aborda la relación entre los conectados de un periodo concesivo en español. En primer lugar, se explica el periodo concesivo. Luego, se discute la clasificación de la relación entre sus cláusulas. A continuación, se enumeran tres parámetros útiles para el análisis de la relación interclausal: a) continuidad tópica entre los conectados, b) iconicidad del orden de las cláusulas y c) función retórica de cada cláusula. Se hace un estudio de casos de estos parámetros a través del estudio de periodos concesivos extraídos de noticias periodísticas.

Palabras clave: periodo concesivo; cláusula; conectados; relación; centro-periferia.
\end{abstract}

\begin{abstract}
This article examines the relationship between connected clauses in Spanish concessive periods. First, concessive periods are explained. Then, the classification of the relation between its clauses is discussed. Below, three useful parameters for relationship between clauses analysis are presented: a) topical continuity between connected clauses, b) iconicity in clauses order and in events order and c) clauses rhetoric functions. These parameters are studied through the analysis of 20 concessive periods taken from press news.

Keywords: concessive period; clause; connected clauses; relationship; center-periphery.
\end{abstract}

\section{Las construcciones concesivas desde un punto de vista semántico-pragmático}

Desde un punto de vista pragmático-semántico, las construcciones concesivas pueden caracterizarse por señalar un estado de cosas que no impide que se lleve a cabo el evento que la oración principal expresa, si bien lo obstaculiza. Esto es lo que Luis Flamenco García (1999, p. 3813), en su artículo de la Gramática descriptiva de la lengua española titulado "Las construcciones concesivas y adversativas", denomina "causa inoperante". Según el autor, las construcciones concesivas se utilizan para destacar dicho obstáculo (por ejemplo, aunque llovía a cántaros fue a la reunión), mientras que las construcciones adversativas destacan el resultado de la superación del obstáculo (por ejemplo, llovía a cántaros, pero fue a la reunión).

Dra. Daniela Soledad Gonzalez. Profesora Adjunta en la Facultad de Filosofía y Letras, Universidad Nacional de Cuyo. Becaria de investigación posdoctoral en el Consejo Nacional de Investigaciones Científicas y Técnicas (CONICET). Mendoza, Argentina. Correo electrónico: gonzalezdanielasoledad@yahoo.com.ar

Recepción: 02- 10- 19

Aceptación: 03- 12- 19 
El obstáculo que presenta la prótasis de un período concesivo puede ser «real»o, mejor dicho, de sentido común (por ejemplo, Aunque llueva torrencialmente, saldré a pasear), o puede considerarse como tal en el modelo cognitivo idealizado que hay en la mente del hablante (por ejemplo, Aunque era su amiga, le dijo que no le había gustado su fiesta). Es decir, el obstáculo que manifiesta la cláusula concesiva hace referencia a una contraexpectativa, por ejemplo, a un factor que el hablante individual (y no el sentido común) considera o no obstáculos para la realización de la cláusula principal (RAE, 2010, p. 915).

El obstáculo expresado por una cláusula concesiva puede ser clasificado como hipotético, por ejemplo en (1a) y (1b), o factual, como en (1c). En el primer tipo de cláusulas, el encabezador equivale a aún en el supuesto de que. Generalmente, contienen tiempos verbales del modo subjuntivo. En el segundo tipo de cláusulas, se designan situaciones que se dan por ciertas en el momento actual o en el futuro, lo cual encuentra su correlato en el uso de tiempos verbales del modo indicativo en general. En algunas ocasiones, se enuncian cláusulas factuales con modo subjuntivo: por ejemplo, Aunque esté ahora borracho, mañana acudirá a la oficina.

(1)

(a) Aunque se lo explicaran, no lo entendería.

(b) Aunque se lo expliquen, no lo entenderá.

(c) Aunque se lo explicaron, no lo entendió.

Es interesante resaltar que el contratiempo que no impide que se realice el evento principal (la explicación) se halla en un extremo de una escala de obstáculos posibles. Esto puede observarse si se descompone el subordinante aunque en sus componentes: el adverbio escalar aún y que. "Si esta posibilidad [...] no es capaz de impedir el hecho denotado por la apódosis [...], tampoco lo harán las situadas por debajo en una escala de obstáculos [...] Así, de Aún si no me invitan formalmente asistiré, se obtiene la inferencia "Asistiré en cualquier caso"" (RAE, 2010, p. 902, negrita propia).

Si bien no es objeto particular de este trabajo el origen del subordinante aunque, es inevitable hacer referencia a un principio establecido en los estudios sobre la gramaticalización acerca de este elemento concesivo, que es la direccionalidad temporal < concesivo (no viceversa) en su gramaticalización. Traugott y Dasher (2002, p. 26) lo explican así

\footnotetext{
The resulting synchronic implicational relationship is of the type 'if a term is concessive it may have derived from a temporal' (e.g. while, however [note the ever here]), or, in a stronger version, 'if $\mathrm{L}$ has temporal and concessive polysemies, then the concessive is with strong probability derived from the temporal'1.
}

\section{Las construcciones concesivas desde un punto de vista sintáctico: problemas clasificatorios}

Las construcciones concesivas aparecen generalmente en una estructura bimembre denominada periodo concesivo, cuyas partes son la prótasis y la apódosis (RAE, 2010, p. 897). En el ejemplo Aunque me lo habían presentado, no lo reconocí, la primera parte,

1 La relación de implicación sincrónica resultante es del tipo 'si un término es concesivo puede haber derivado de un temporal' (por ejemplo, mientras que, aunque [note el aún aquí]), o, en una versión más fuerte, «si L tiene polisemias temporales y concesivas, entonces la concesiva ha sido, muy probablemente, derivada de la temporal〉 (traducción propia). 
la cláusula que encabeza el subordinante aunque, es la prótasis y la segunda parte es la apódosis o cláusula principal.

Según la RAE (2010, pp. 919-921),

se suele llamar conectores a unas palabras muy breves que enlazan dos elementos entre sí y parecen no tener vida independiente. Cuando estos elementos son dos frases nominales o un verbo o adjetivo y una frase nominal, el conector se llama preposición: café con leche, harto de sus caprichos, trabaja para su familia.

López García (2005, p. 219) señala que "cuando los elementos enlazados son dos oraciones o un verbo y una oración hablaremos de conjunción: vino y se quedó, si llueve no iré, dijo que prefería pescado".

Las marcas de concesividad pueden cumplir la función sintáctica de conector o la de subordinante de una cláusula incluida. Son consideradas como conectores cuando actúan como locuciones adverbiales en sí mismas, sin introducir una cláusula subordinada (por ejemplo, así y todo, mal que le pese, con todo, de todas maneras, de todos modos, en cualquier caso) (RAE, 2010, p. 597).

López García (2005) habla de subordinación para el caso de la concesividad. Las marcas de concesividad pueden ser consideradas como encabezadores de subordinadas adverbiales impropias (RAE, 2010, p. 898), cuando se trata de construcciones fijas concesivas introducidas por subordinantes. Se las llama impropias porque no son conmutables por adverbios. A continuación, la explicación de la RAE (2010, p. 899):

\footnotetext{
Así, el segmento subrayado en Bajaré la basura, aunque no me apetece no constituye un modificador modal, temporal o de otro tipo, que delimite la acción expresada por el verbo bajar o por el grupo verbal bajar la basura, sino que introduce, en un segmento separado por una pausa, un estado de cosas que no impide que se lleve a cabo el evento que la oración principal expresa. Se suele decir que las relaciones entre prótasis y apódosis están más próximas a las conexiones lógicas, o en general argumentativas, que se dan entre premisas y conclusiones que a las que existen entre los predicados verbales y sus modificadores. Las prótasis correspondientes a estos períodos no constituyen, en suma, modificadores del predicado verbal, y no se considera correcto en la actualidad interpretarlos como complementos circunstanciales suyos.
}

Además de los conectores concesivos y de las cláusulas concesivas con encabezador, existen otros modos de expresar la concesividad en español. Algunos de esos modos son las proposiciones sin conector (por ejemplo, Siendo joven, es calvo) y el esquema verbo en subjuntivo + relativo + verbo en subjuntivo (por ejemplo, Sea usted quien sea, se alegrará de verlo).

Existen variados subordinantes concesivos. El más prototípico, menos marcado y más frecuentemente usado es aunque, pero hay muchos más, como incluso (+ gerundio / si), ni siquiera, aun (+ gerundio) y si bien.

\section{La relación sintáctica entre los conectados de las cláusulas concesivas}

Las cláusulas concesivas no cumplen una función nuclear dentro de la cláusula «principal», no se trata de modificadores de función nuclear. La prótasis no está incluida en la apódosis; por este motivo no puede hablarse de subordinación.

La subordinación es explicada por Gili Gaya (2000 [1943], párr. 216) de la siguiente manera: "Toda oración subordinada se halla incorporada a la principal, y guarda con ella la misma relación que guardan con el verbo los elementos sintácticos de la oración simple”. 
La coordinación es un procedimiento gramatical por el que se establece equivalencia sintáctica entre los conectados. Ningún constituyente forma parte de otro. Además, hay una mayor autonomía sintáctica de las cláusulas. Entre las cláusulas de un periodo concesivo no hay coordinación. No se trata de dos constantes puestas al mismo nivel jerárquico, sino que la cláusula concesiva modifica a una cláusula de mayor rango jerárquico.

Lapesa (1978) habla de co-subordinación en casos como Ha llovido, porque el suelo está mojado. Según el autor, se trata de una subordinación de ambos conectados a un verbo de lengua implícito, en función de objeto directo uno y de circunstancial el otro. El enunciado completo sería Digo (ha llovido), (porque el patio está mojado). Rojo (1978) y Narbona (1990), por su parte, hablan de interordinación: oraciones bipolares en las que se da una relación de ordinación o interdependencia entre sus dos componentes, que se presuponen mutuamente.

Las cláusulas concesivas funcionan como modificadores de las cláusulas principales completas, no están incluidas en ellas (subordinación) ni al mismo nivel de estas (coordinación). Entre ambas cláusulas hay una relación de modificador periférico + núcleo oracional (Kovacci, 1992, pp. 144-156).

Fernández Lagunilla y Anula Rebollo (1995) señalan dos clases de proposiciones: adjuntas del SV (son las de tiempo, lugar y modo) y adjuntas de toda la oración principal (aquí se ubican las causales, finales, condicionales, concesivas). Los autores ubican las cláusulas concesivas dentro de la función de proposiciones subordinadas adverbiales adjuntas, por ejemplo, no seleccionadas semánticamente por el verbo de la cláusula principal, o de centroperiferia, como plantean Borzi (2001 y 2010) y Morón Usandivaras (2012 y 2015).

Matthiessen y Thompson (1988) rescatan la distinción subordinación núcleo-satélite. Este tipo de conexión sintáctica se produce entre dos cláusulas; una de ellas presenta la información más importante o focalizada y la otra introduce información suplementaria o periférica (propósito, condición, concesión, etc.).

La denominación centro-periferia hace referencia al tipo de información que introduce cada conectado. La cláusula centro presenta información discursivamente central, que el hablante destaca o pone en foco. La cláusula periferia introduce información presentada como conocida, que funciona discursivamente como marco de la información central (Morón Unsandivaras, 2015, p. 137).

Ahora bien, no todas las cláusulas concesivas son de la misma clase. Su valor es discursivo, pueden actuar como modificadores periféricos del núcleo oracional o dictum, o como modificadores de modalidad o modus. La RAE (2010, p. 917) utiliza las denominaciones concesivas del enunciado y concesivas de la enunciación, respectivamente. Un ejemplo de modificador del dictum es Aunque está enfermo va a la oficina. Hay una relación dentro del enunciado entre los elementos conectados: es el hecho de ir a la oficina el que no se ve obstaculizado por la enfermedad. Un ejemplo de concesiva con función de modificador del modus es Aunque él lo niegue, [yo digo que] irá a la oficina. En este caso, como lo pone de manifiesto la catálisis de "yo digo que", el hecho de que "él lo niegue" está relacionado con el acto de decir del enunciador: es el acto de decir del enunciador (y no el ir o no a la oficina), lo que no se ve impedido por la negación mencionada. 


\section{Parámetros para analizar las construcciones centro-periferia}

El tipo de relación pragmática, semántica y sintáctica entre los conectados de un periodo concesivo se determina en cada combinación de cláusulas en su contexto de uso. Se obtiene como el resultado de una combinación de atributos entre los cuales se encuentran los siguientes: distribución de la información entre las cláusulas, continuidad tópica entre los conectados, continuidad tópica hacia la derecha en el discurso (o hacia adelante, en el caso de la oralidad), tipos de causa, posición de las cláusulas, iconicidad del orden de las cláusulas respecto del orden de los eventos y presencia de pausa previa al conector.

Aquí, por cuestiones de espacio, se analizarán los siguientes: a) continuidad tópica entre los conectados, b) función retórica de cada cláusula, e c) iconicidad del orden de las cláusulas respecto del orden de los eventos. La elección de estos parámetros responde al modelo de Morón Unsandivaras (2012, p. 7). Se aplica este análisis a una muestra de períodos concesivos extraídos de noticias de los diarios La Nación, Clarín, Los Andes y UNO.

A continuación, se explicará en qué consiste cada parámetro y se lo ejemplificará con un enunciado concesivo. El primer parámetro es el de la continuidad tópica entre los conectados. El término proviene de Bentivoglio (1983) y hace referencia a la combinación de tres parámetros: a) continuidad/discontinuidad de la identificación del designado de un nominal que funciona como tópico en relación con las cláusulas que le preceden, b) permanencia de la identificación del designado de un determinado nominal en las cláusulas siguientes y c) el hecho de que el nominal del tópico bajo estudio pueda tener un designado único o no.

Como señala Morón Unsandivaras (2012, p. 234), la continuidad tópica se observa en el discurso (además de entre las cláusulas de un periodo causal/condicional/concesivo). Puede ser a la derecha o a la izquierda. Se manifiesta en la desinencia verbal de persona y número, en los usos pronominales, en la repetición de argumentos y en la sinonimia. Un ejemplo de enunciado con baja continuidad tópica entre las cláusulas conectadas y el discurso posterior es el siguiente. Se trata del título de una noticia y el copete:

(2)

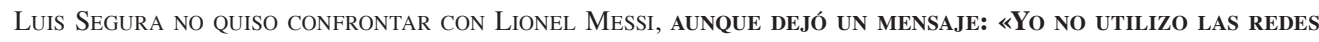
SOCIALES PARA DISCUTIR»

Luego de la crítica del capitán de la selección, llegó la respuesta del dirigente

(La Nación, 25/06/16).

La cláusula concesiva se encuentra destacada. En este enunciado, puede observarse que hay un periodo concesivo con dos cláusulas. La primera es Luis Segura no quiso confrontar con Lionel Messi y la segunda es aunque dejó un mensaje: «Yo no utilizo las redes sociales para discutir». La cláusula concesiva, que se presenta pospuesta, manifiesta una continuidad del referente Luis Segura en la desinencia de primera persona de los verbos dejó y utilizo, y en el pronombre de primera persona singular (yo). El copete, Luego de la crítica del capitán de la selección, llegó la respuesta del dirigente, presenta una continuidad tópica baja a la derecha, pues retorna a la izquierda al momento temporal anterior a la respuesta de Segura (Luego de la crítica del capitán de la selección) para después volver a repetir que el dirigente dio una respuesta. 
En cambio, el siguiente enunciado manifiesta una alta continuidad tópica entre los enunciados y el discurso previo y posterior:

(3)

\begin{abstract}
MARTINO: «LO ÚNICO QUE ME PREOCUPA ES GANAR EL PARTIDO DE MAÑANA»
El entrenador del seleccionado argentino dejó en claro que está dispuesto a resignar el buen juego con tal de ganar la Copa América mañana.

El seleccionador de fútbol de Argentina, Gerardo Martino, dejó de lado este sábado sus principios y dijo que su equipo tiene que ganar la final de la Copa América Centenario ante Chile sin importar si juega bien o mal.

«Lo único que me preocupa es ganar el partido de mañana», dijo Martino a la prensa en el estadio MetLife en East Rutherford (Nueva Jersey, este de Estados Unidos), escenario del gran choque, revancha de la final del último torneo sudamericano ganado por la Roja (Los Andes, 25/06/2016, negrita propia).
\end{abstract}

En este discurso, los argumentos principales, 'Martino' y 'seleccionado argentino', son retomados a la derecha como entrenador y equipo argentino. El entrenador es también retomado con su nombre completo, Gerardo Martino. También se retoma en las desinencias de los verbos dejó, está, dejó de lado, dijo y en el pronombre OI me (me preocupa). El equipo argentino es retomado en las desinencias de los verbos tiene que ganar y juega.

El segundo parámetro de análisis es la función retórica de las cláusulas. La función retórica es la intención comunicativa que manifiesta el hablante en cada conectado: afirmar, hipotetizar, preguntar, exhortar, aconsejar, expresar un deseo o un sentimiento, explicar, etc. Si las dos cláusulas comparten la misma función retórica, se considera que hay un solo acto de habla mientras que, si las cláusulas presentan distintas intenciones, se está ante dos actos de habla diferentes (Morón Unsandivaras, 2012, p. 9).

Obsérvese el siguiente fragmento:

(4)

Y aunque la ciudad alemana de Fráncfort podría beneficiarse de la fuga de banqueros y financistas de la city londinense, no se sabe cómo se verá afectado el comercio bilateral. (Viceconte, Clarín, 25/06/16, negrita propia).

En este fragmento, el periodo concesivo presenta una hipótesis en el primer conectado y una afirmación en el segundo. Hay dos actos de habla distintos. Habría que observar con un análisis cuantitativo de corpus si lo más prototípico en este tipo de cláusulas es que manifiesten un acto de habla idéntico al de las cláusulas con las que constituyen periodo, o si, por el contrario, expresan un acto de habla que matiza otro acto de habla (por ejemplo, que la cláusula concesiva hipotetice y la conectada a ella asevere). También puede suceder que se corrobore que ambos comportamientos se producen en igual medida en la concesividad.

El tercer parámetro de análisis es la iconicidad del orden de las cláusulas respecto del orden de los eventos. Trasladando lo propuesto por Morón Unsandivaras (2012 y 2015) para las cláusulas causales, ¿cómo sería el orden icónico de la construcción concesiva? La causa u obstáculo inoperante precedería temporalmente a la consecuencia, por lo tanto, la cláusula concesiva icónica se encontraría en posición antepuesta. El orden sería no icónico cuando la cláusula concesiva se encuentre en posición pospuesta. Este sería el funcionamiento prototípico de las construcciones concesivas, pues hay enunciados en los que no puede hallarse una relación temporal tan clara entre la causa inoperante y el evento principal ${ }^{2}$. En el ejemplo

2 Esto, además de otros casos de construcciones con conectores concesivos que cumplen funciones adversativas. 
que sigue, se observa un orden no icónico en los conectados, pues el evento de confirmar la información debe suceder a la presentación de esta.

\section{(5)}

Domínguez aseguró que el campeón del presente torneo sumará un título oficial, por lo que si Argentina se consagra, alcanzará a Uruguay con 15 . Además, aunque aún no está confirmado, jugaría una final del mundo ante el ganador de la Eurocopa 2016 (UNO, 25/06/16, negrita propia).

\section{Prueba piloto de análisis}

A continuación, en la Tabla 1, se presenta una prueba piloto del análisis de las relaciones entre los conectados de un periodo concesivo con el fin de predecir los comportamientos prototípicos de estas cláusulas. Se trata del análisis de veinte casos tomados de los diarios $L a$ Nación, UNO, Los Andes y Clarín. Se eligió este corpus porque los textos periodísticos ostentan una fuerte carga argumentativa, lo que los hace un lugar especial para el uso de estrategias concesivas y desmentidas. Las predicciones que se obtengan deben ser complementadas con estudios posteriores más profundos, que revisen corpus significativamente más extensos y cuenten con un tratamiento estadístico de los datos.

Tabla 1. Relaciones semánticas y pragmáticas entre conectados en el periodo concesivo

\begin{tabular}{|c|c|c|c|}
\hline Periodo & $\begin{array}{c}\text { Continuidad } \\
\text { tópica } \\
\text { discursiva }\end{array}$ & $\begin{array}{c}\text { Orden de las } \\
\text { cláusulas en } \\
\text { relación con } \\
\text { los eventos }\end{array}$ & $\begin{array}{c}\text { Funciones } \\
\text { retóricas de } \\
\text { los conectados }\end{array}$ \\
\hline $\begin{array}{c}\text { Luis Segura no quiso confrontar con Lionel Messi, } \\
\text { aunque dejó un mensaje: «Yo no utilizo las redes } \\
\text { sociales para discutir» } \\
\text { (La Nación, 25/06/16, negrita propia). }\end{array}$ & Baja & Icónico & Las mismas \\
\hline $\begin{array}{c}\text { El seleccionador de fútbol de Argentina, Gerardo } \\
\text { Martino, dejó de lado este sábado sus principios } \\
\text { y dijo que su equipo tiene que ganar la final de la } \\
\text { Copa América Centenario ante Chile sin importar si } \\
\text { juega bien o mal }\end{array}$ & Alta & Icónico & Las mismas \\
$\begin{array}{c}\text { (Los Andes, 25/06/2016, negrita propia). } \\
\text { Y aunque la ciudad alemana de Fráncfort podría } \\
\text { beneficiarse de la fuga de banqueros y financistas } \\
\text { de la city londinense, no se sabe cómo se verá } \\
\text { afectado el comercio bilateral (Viceconte, Clarín, } \\
25 / 06 / 16, \text { negrita propia). }\end{array}$ & Alta & No icónico & Distintas \\
\hline $\begin{array}{c}\text { Además, aunque aún no está confirmado, jugaría } \\
\text { una final del mundo ante el ganador de la Eurocopa } \\
\text { 2016 (UNO, 25/06/16, negrita propia). }\end{array}$ & Alta & Icónico & Distintas \\
\hline
\end{tabular}




\begin{tabular}{|c|c|c|c|}
\hline $\begin{array}{l}\text { Siempre atentos al humor de sus potenciales clientes, } \\
\text { algunos "lúcidos" estrategas del marketing masivo } \\
\text { comenzaron a reemplazar a los entusiastas y pujantes } \\
\text { vendedores por máquinas con mensajes grabados, } \\
\text { aparatos que no sólo resultan más económicos } \\
\text { sino que no tienen madre con quien el indefenso } \\
\text { cliente pueda desquitarse. Y si bien no tenemos } \\
\text { nada personal contra los vendedores telefónicos } \\
\text { (quienes también son víctimas de los que impulsan } \\
\text { estas modalidades de venta en las empresas), por } \\
\text { si acaso usted prefiriera mantenerlos alejados de su } \\
\text { vida (y de su teléfono), nada mejor que conocer sus } \\
\text { tácticas (Chretien, Clarín, } 27 / 11 / 2019 \text {, negrita propia). }\end{array}$ & Alta & Icónico & Las mismas \\
\hline $\begin{array}{c}\text { Por si acaso usted prefiriera mantenerlos alejados de } \\
\text { su vida (y de su teléfono), nada mejor que conocer } \\
\text { sus tácticas. Se trate del producto o empresa } \\
\text { de que se trate, estos jóvenes entusiastas son } \\
\text { entrenados de manera idéntica para repetir una y } \\
\text { otra vez las mismas técnicas, las que en ocasiones } \\
\text { nos hacen responder de forma automática de manera } \\
\text { de conseguir su objetivo sin que siquiera nos demos } \\
\text { cuenta (Viceconte, Clarín, } 25 / 06 / 2016, \text { negrita } \\
\text { propia). }\end{array}$ & Baja & Icónico & Las mismas \\
\hline $\begin{array}{c}\text { Fue claro en el sentido de que no volverá a Atlético } \\
\text { Tucumán, más allá de que dejó la puerta abierta } \\
\text { para irse de Colón (Clarín, 28/11/2019, negrita } \\
\text { propia). }\end{array}$ & Alta & Icónico & Las mismas \\
\hline $\begin{array}{c}\text { Bautista necesitó más de tres horas para imponerse } \\
\text { por 7-5, 6-4, 3-6 y 6-3 a Pella, que nunca antes había } \\
\text { llegado tan lejos en un torneo del Grand Slam y que, } \\
\text { pese a haber jugado partidos muy largos desde la } \\
\text { primera ronda, presentó una muy dura resistencia } \\
\text { (Los Andes, 10/07/2019a, negrita propia). }\end{array}$ & Alta & Icónico & Las mismas \\
\hline $\begin{array}{c}\text { "(Desfiles como el de ayer) Son una comunión entre } \\
\text { las Fuerzas Armadas y el pueblo; la gente valora } \\
\text { mucho las Fuerzas Armadas, aunque nos hayan } \\
\text { hecho creer que la gente no las quería (Los Andes, } \\
\text { 10/07/2019b, negrita propia). }\end{array}$ & Alta & No icónico & Las mismas \\
\hline $\begin{array}{l}\text { Tras su emisión, Beto Casella le preguntó a la rubia } \\
\text { si el actor le había escrito por redes sociales, pese a } \\
\text { confesar de que prefería el coqueteo cara a cara. } \\
\text { Ella confirmó el contacto: "Sí, me mandó. ¿Si hubo } \\
\text { respuesta? Sí, emojis, caritas, corazoncitos", dijo (Los } \\
\text { Andes, 2/07/2019, negrita propia). }\end{array}$ & Alta & No icónico & Las mismas \\
\hline
\end{tabular}




\begin{tabular}{|c|c|c|c|}
\hline $\begin{array}{l}\text { Las cantidades de cambios y el alcance de los } \\
\text { impactos futuros de la tecnología no son bien } \\
\text { conocidos por quienes deben adoptar decisiones } \\
\text { tanto en el campo político, empresarial o social. } \\
\text { Ello se explica porque se desconocen las tecnologías } \\
\text { disponibles y aquellas que vendrán en un futuro } \\
\text { próximo. Si bien se menciona el cambio en casi } \\
\text { todos los discursos políticos, y empresariales } \\
\text { no se han asignado recursos a la información que } \\
\text { permita anticipar los impactos intersectoriales de } \\
\text { las tecnologías radicales y las innovaciones sociales } \\
\text { (Gutiérrez, Los Andes, 10/07/2019, negrita propia). }\end{array}$ & Alta & Icónico & Las mismas \\
\hline $\begin{array}{l}\text { Actualmente el producto se encuentra agotado, de } \\
\text { acuerdo con la web y según confirmó Belle Delphine } \\
\text { en un video de Instagram el } 4 \text { de julio, en el que } \\
\text { prometió que "pronto" habrá más, aunque confesó } \\
\text { que "estos días han sido muy extraños" al tener } \\
\text { que tomar tantos baños. "No esperaba que tanta } \\
\text { gente estuviera interesada", admitió la modelo (Los } \\
\text { Andes, 10/07/2019c, negrita propia). }\end{array}$ & Alta & No icónico & Las mismas \\
\hline $\begin{array}{c}\text { Sobre esa condena la abogada señaló: "En este } \\
\text { caso teníamos un antecedente donde ya había una } \\
\text { sentencia penal, así y todo existieron publicaciones } \\
\text { posteriores donde lo único que se utilizaba eran } \\
\text { hashtags pero que previamente habían sido utilizados } \\
\text { con nombre y apellidos" (La Nación, 26/11/2019, } \\
\text { negrita propia). }\end{array}$ & Baja & Icónico & Las mismas \\
\hline $\begin{array}{l}\text { También confirmaron que Héctor Maldonado, } \\
\text { el conductor del micro de } 48 \text { años, que continúa } \\
\text { detenido e incomunicado, podrá declarar mañana y } \\
\text { que el test de alcoholemia le dio negativo aunque los } \\
\text { resultados del análisis de sangre demorarán cerca } \\
\text { de una semana (UNO, 28/11/2019a, negrita propia). }\end{array}$ & Baja & Icónico & Las mismas \\
\hline $\begin{array}{c}\text { El último miércoles por la noche hubo un } \\
\text { acuerdo entre el sector del presidente de la UCR } \\
\text { y diputado nacional electo por Mendoza, Alfredo } \\
\text { Cornejo, y el del gobernador de Jujuy, Gerardo } \\
\text { Morales, para desactivar la pelea por la presidencia } \\
\text { del bloque de diputados de la UCR y ratificar en el } \\
\text { puesto a Mario Negri. } \\
\text { Si bien esto se logró (principalmente porque Negri } \\
\text { siempre tuvo los votos necesarios en el bloque } \\
\text { para ganar la pulseada), trascendió que el acuerdo } \\
\text { alcanzaba al Senado, lo cual horas después fue } \\
\text { rechazado por distintas fuentes partidarias (UNO, } \\
28 / 11 / 2019 b \text {, negrita propia). }\end{array}$ & Alta & Icónico & Las mismas \\
\hline
\end{tabular}




\begin{tabular}{|c|c|c|c|}
\hline $\begin{array}{c}\text { "Creo que fuera de que cada uno puede tener } \\
\text { su opinión y la respeto, todo el mundo se puso a } \\
\text { opinar de Bollywood porque fue un verano tranquilo } \\
\text { mediáticamente en donde el "tema" del verano fue } \\
\text { mi obra y hablando de mi obra mucha gente logró } \\
\text { una visibilidad que no tenían", agregó el dramaturgo } \\
\text { (UNO, 8/02/2018, negrita propia). }\end{array}$ & Alta & Icónico & Las mismas \\
\hline $\begin{array}{c}\text { La mayor parte de los analistas consideran que este } \\
\text { atajo de emergencia que implica volver a poner } \\
\text { en marcha de denominada "maquinita" tienen sus } \\
\text { riesgos, aunque admiten que el Gobierno acudió a } \\
\text { este mecanismo ante el cierre total del resto de los } \\
\text { canales de financiamiento (La Nación, 27/11/2019, } \\
\text { negrita propia). }\end{array}$ & Alta & No icónico & Las mismas \\
\hline $\begin{array}{c}\text { Este es el valor más caro en toda la serie de costos de } \\
\text { esa vivienda en términos de salarios y esta relación } \\
\text { la iniciamos en 1990, aunque podría ser estudiada } \\
\text { con fechas anteriores (Ferreres, } L a \text { Nación, } \\
27 / 11 / 2019, \text { negrita propia). }\end{array}$ & Alta & No icónico & Las mismas \\
\hline $\begin{array}{c}\text { En el caso de Tienda Mía, se podrán aprovechar } \\
\text { los descuentos de hasta } 80 \text { por ciento de esos } \\
\text { sitios, comprar al mismo precio que en EE.UU., sin } \\
\text { gastos de envíos internacionales, aunque al precio } \\
\text { final habrá que sumarle otros componentes } \\
\text { que configuran el costo del producto: esto es, } \\
\text { por ejemplo, el valor por kilo, que obviamente } \\
\text { encarecerá el costo inicial }(L a \text { Nación, } 29 / 11 / 2019, \\
\text { negrita propia). }\end{array}$ & Alta & No icónico & Las mismas \\
\hline $\begin{array}{c}\text { A pesar de tener más de veinte años de } \\
\text { trayectoria, Facundo Arana nunca hizo temporada } \\
\text { en Carlos Paz (La Nación, } 28 / 11 / 2019, \text { negrita } \\
\text { propia). }\end{array}$ & Alta & Icónico & Las mismas \\
\hline
\end{tabular}

Se consideró que la continuidad tópica era alta cuando se mantenía en la cláusula concesiva la identidad de un elemento del otro conectado o del fragmento discursivo anterior/ posterior en los usos pronominales, en la repetición de argumentos, en la sinonimia, en la desinencia verbal o en la conexión sujeto/predicado no verbal con un verboide en el predicado. Por ejemplo, en el siguiente enunciado, se mantiene el tópico "Bautista", pues es el sujeto de haber jugado partidos muy largos desde la primera ronda y de presentó una muy dura resistencia:

(6)

Bautista necesitó más de tres horas para imponerse por 7-5, 6-4, 3-6 y 6-3 a Pella, que nunca antes había llegado tan lejos en un torneo del Grand Slam y que, pese a haber jugado partidos muy largos desde la primera ronda, presentó una muy dura resistencia (Los Andes, 10/07/2019a, negrita propia).

En el siguiente caso, la continuidad tópica se produce por la repetición del argumento "la gente", que tiene como sinónimo textual "el pueblo": 
(7)

"(Desfiles como el de ayer) Son una comunión entre las Fuerzas Armadas y el pueblo; la gente valora mucho las Fuerzas Armadas, aunque nos hayan hecho creer que la gente no las quería (Los Andes, 10/07/2019b, negrita propia).

En el próximo ejemplo, se puede apreciar la continuidad tópica en el hecho de que el referente de "esto" en la cláusula concesiva "si bien esto no se logró" es la situación descripta en el párrafo precedente:

(8)

El último miércoles por la noche hubo un acuerdo entre el sector del presidente de la UCR y diputado nacional electo por Mendoza, Alfredo Cornejo, y el del gobernador de Jujuy, Gerardo Morales, para desactivar la pelea por la presidencia del bloque de diputados de la UCR y ratificar en el puesto a Mario Negri.

Si bien esto se logró (principalmente porque Negri siempre tuvo los votos necesarios en el bloque para ganar la pulseada), trascendió que el acuerdo alcanzaba al Senado, lo cual horas después fue rechazado por distintas fuentes partidarias (UNO, 28/11/2019, negrita propia).

Es necesario aclarar que hay grados en el establecimiento y el mantenimiento de un tópico discursivo. Aquí solo se ha considerado la opción entre una continuidad tópica alta y una baja, pero podría haberse agregado una media. Las distinciones más sutiles quedan pendiente para estudios más detallados. El siguiente caso podría considerarse como un ejemplo de continuidad tópica media, pues el elemento que será retomado a la derecha es "opinión” y se lo retoma a través de una palabra con la misma base léxica: el verbo "opinar":

(9)

"Creo que fuera de que cada uno puede tener su opinión y la respeto, todo el mundo se puso a opinar de Bollywood porque fue un verano tranquilo mediáticamente en donde el "tema" del verano fue mi obra y hablando de mi obra mucha gente logró una visibilidad que no tenían”, agregó el dramaturgo (UNO, 8/02/2018, negrita propia).

Respecto del parámetro "función retórica de los conectados del periodo concesivo", se consideró que cuando en ambos conectados primaba la función asertiva, los actos de habla eran los mismos, como puede apreciarse en el fragmento que sigue:

Luis Segura no quiso confrontar con Lionel Messi, aunque dejó un mensaje: «Yo no utilizo las redes sociales para discutir» (La Nación, 25/06/16).

La prótasis es aseverativa negativa y la apódosis es aseverativa afirmativa. En cambio, en el siguiente fragmento, se observa disparidad en las funciones retóricas de prótasis y apódosis, puesto que en el primer conectado, que es la cláusula concesiva, se presenta una afirmación y en el segundo conectado se presenta una hipótesis.

(11)

Además, aunque aún no está confirmado, jugaría una final del mundo ante el ganador de la Eurocopa 2016 (UNO, 25/06/16, negrita propia).

En algunos casos, se encontraron tiempos verbales correspondientes al modo subjuntivo en uno de los conectados mientras que en el otro había tiempos del indicativo. No se asoció automáticamente el uso de tiempos del modo subjuntivo a la duda (e incluso a la hipotetización), sino que se analizó que la utilización del modo subjuntivo indicaba subordinación en un plano de afirmación desde la subjetividad, como se puede apreciar en el siguiente fragmento, en el que la perífrasis hayan hecho creer lleva a cabo una clara aseveración subjetiva: 
(12)

“(Desfiles como el de ayer) Son una comunión entre las Fuerzas Armadas y el pueblo; la gente valora mucho las Fuerzas Armadas, aunque nos hayan hecho creer que la gente no las quería (Los Andes, 10/07/2019b, negrita propia).

No se apreciaron variaciones fuertes entre los actos de habla implicados en el periodo concesivo. Solo se hallaron actos asertivos y dubitativos o hipotetizadores. En el corpus analizado, los actos de habla de estos tipos se enmarcan en construcciones discursivas explicativo-argumentativas.

El último parámetro de análisis, la iconicidad del orden de las cláusulas, se analizó teniendo en cuenta el orden de los eventos de los conectados en una línea temporal. Los eventos son de dos naturalezas: obstáculos fácticos (la mayoría de los casos) y obstáculos en un plano de abstracción, como es el que se ejemplifica con el siguiente fragmento:

\section{(13)}

Siempre atentos al humor de sus potenciales clientes, algunos "lúcidos" estrategas del marketing masivo comenzaron a reemplazar a los entusiastas y pujantes vendedores por máquinas con mensajes grabados, aparatos que no sólo resultan más económicos sino que no tienen madre con quien el indefenso cliente pueda desquitarse. Y si bien no tenemos nada personal contra los vendedores telefónicos (quienes también son víctimas de los que impulsan estas modalidades de venta en las empresas), por si acaso usted prefiriera mantenerlos alejados de su vida (y de su teléfono), nada mejor que conocer sus tácticas (Chretien, Clarín, 27/11/2019, negrita propia).

En este caso, el hecho de que el hablante no tenga ningún problema personal contra los vendedores telefónicos no es un obstáculo para lo que va a decir a continuación. Como el tener o no algún reparo sobre algo de algún modo precede al tipo de opinión que se tiene acerca de ello, se considera que el orden de los eventos en el periodo concesivo es icónico.

En algunos fragmentos del corpus, el orden de los eventos no implica una ventana muy amplia entre un evento y el otro. Esto sucede en el extracto (14):

\section{(14)}

Las cantidades de cambios y el alcance de los impactos futuros de la tecnología no son bien conocidos por quienes deben adoptar decisiones tanto en el campo político, empresarial o social. Ello se explica porque se desconocen las tecnologías disponibles y aquellas que vendrán en un futuro próximo. Si bien se menciona el cambio en casi todos los discursos políticos, y empresariales no se han asignado recursos a la información que permita anticipar los impactos intersectoriales de las tecnologías radicales y las innovaciones sociales (Gutiérrez, Los Andes, 10/07/2019, negrita propia).

En este ejemplo, se puede apreciar que la acción de mencionar el cambio en los discursos sucede paralelamente al no asignar recursos para producir innovaciones sociales.

Para cerrar este apartado, la Tabla 2 resumen los resultados que arroja el estudio de casos. Las frecuencias absolutas o cantidad de casos de cada categoría analizada son las siguientes:

Tabla 2. Resultados del estudio de casos: frecuencias absolutas

\begin{tabular}{|c|c|c|c|c|c|}
\hline \multicolumn{2}{|c|}{$\begin{array}{c}\text { Continuidad tópica } \\
\text { discursiva }\end{array}$} & \multicolumn{2}{c|}{$\begin{array}{c}\text { Orden de las cláusulas en } \\
\text { relación con los eventos }\end{array}$} & \multicolumn{2}{c|}{$\begin{array}{c}\text { Funciones retóricas de los } \\
\text { conectados }\end{array}$} \\
\hline Baja & 4 & No icónico & 7 & Las mismas & 18 \\
\hline Alta & 16 & Icónico & 13 & Distintas & 2 \\
\hline
\end{tabular}

Las frecuencias porcentuales o porcentajes de aparición de los parámetros analizados en la muestra son las que se detallan en la Tabla 3: 
Tabla 3. Resultados del estudio de casos: frecuencias porcentuales

\begin{tabular}{|c|c|c|c|c|c|}
\hline \multicolumn{2}{|c|}{$\begin{array}{c}\text { Continuidad tópica } \\
\text { discursiva }\end{array}$} & \multicolumn{2}{c|}{$\begin{array}{c}\text { Orden de las cláusulas en } \\
\text { relación con los eventos }\end{array}$} & \multicolumn{2}{c|}{$\begin{array}{c}\text { Funciones retóricas de los } \\
\text { conectados }\end{array}$} \\
\hline Baja & $20 \%$ & No icónico & $35 \%$ & Las mismas & $90 \%$ \\
\hline Alta & $80 \%$ & Icónico & $65 \%$ & Distintas & $10 \%$ \\
\hline
\end{tabular}

Con respecto a la continuidad tópica entre los conectados del periodo, resultó ser muy alta, pues representa un $80 \%$ del total. El orden de las cláusulas en relación con los eventos tuvo una distribución más pareja; de todos modos, predominó un orden icónico (65 \% de los casos). Por último, las funciones retóricas de los conectados fueron coincidentes en la mayoría de los casos (90\% del total).

Escapa al alcance de este trabajo hacer una interpretación cognitiva, lógica e incluso filosófica de lo que subyace a los usos analizados. Este artículo se centra en identificar algunos parámetros que pueden resultar de utilidad para la descripción del comportamiento del periodo concesivo en español y en llevar a cabo una prueba piloto que pueda aportar a estudios de alcance mayor, focalizados en la determinación de las propiedades pragmáticas y semánticas de los períodos concesivos.

\section{Conclusión}

Las construcciones concesivas del español no pueden encasillarse ni en la coordinación ni en la subordinación. Ilustran un tercer tipo de relación interclausal, que algunos autores han comprendido como co-subordinación y otros como interdependencia. La terminología que parece más feliz es la de relación centro-periferia (Borzi, 2010; Morón Unsandivaras, 2015). Según esta postura, existe un continuum en las relaciones pragmáticas, semánticas y sintácticas entre las cláusulas conectadas. Aunque todas las cláusulas concesivas manifiestan el mismo tipo de relación sintáctica, cada una de ellas posee distintos grados de prototipicidad. Para establecer algunos patrones de comportamiento que ayuden a delimitar el modo de funcionamiento del periodo concesivo prototípico, se analizan en este trabajo algunos parámetros tomados de los estudios de Morón Unsandivaras (2012 y 2015). Dichos parámetros son los siguientes: 1) la continuidad tópica entre los conectados; 2) la iconicidad en el orden de presentación de los eventos; 3 ) las funciones retóricas de los conectados.

A partir de una prueba piloto realizada sobre veinte casos y siguiendo los criterios enumerados, se predicen los siguientes comportamientos de las construcciones concesivas: 1) las cláusulas concesivas típicas manifiestan una alta continuidad tópica entre los conectados; 2) su orden es icónico al orden de los eventos; 3) las funciones retóricas de los conectados de los períodos concesivos suelen coincidir y suelen ser asertivas.

Para fundamentar mejor estas predicciones, serían necesarios estudios de corpus más exhaustivos con análisis cuantitativos que confirmen estadísticamente que, efectivamente, estos usos se producen en la mayoría de los casos. En estos estudios, se podría hilar fino en el análisis de los criterios analizados aquí, correlacionar los parámetros que se han tomado en consideración y experimentar con otros parámetros. Incluso, sería interesante llevar a cabo un análisis de este tipo diferenciado para cada uno de los diversos marcadores de concesividad. 


\section{Bibliografía}

Bentivoglio, P. (1983). Topic Continuity and Discontinuity in Discourse: A study of spoken Latin-American Spanish. En T. Givón (Ed.), Topic Continuity in Discourse: Quantitive Cross Language Study (pp. 259-311). Amsterdan/Philadelphia: John Benjamins.

Borzi, C. (2001). Coordinación y subordinación: zonas de una ojiva. En E. de Arnoux y A. Di Tullio (Eds.), Volumen Homenaje a Ofelia Kovacci (pp. 91-112). Buenos Aires: EUDEBA.

Borzi, C. (2010). Teóricos $N^{o} 13$ y 15. Universidad de Buenos Aires: Cátedra: Gramática C, Facultad de Filosofía y Letras.

Chretien, M. (27 de noviembre de 2019). Clientes furiosos con los estrategas del marketing. Clarín. Recuperado de https://www.clarin.com/cartas-al-pais/clientes-furiososestrategas-marketing_0_uja2VAJV.html

Diario Clarín. (28 de noviembre de 2019). El Pulga Rodríguez dio una definición contundente sobre su futuro en el fútbol. Recuperado de https://www.clarin.com/deportes/pulgarodriguez-atletico-tucuman-volver_0_ye7MBpDe.html

Diario La Nación. (25 de junio de 2016). Luis Segura no quiso confrontar con Lionel Messi, aunque dejó un mensaje: "Yo no utilizo las redes sociales para discutir". Recuperado de http://www.lanacion.com.ar/1912625-luis-segura-no-quiso-confrontar-con-lionelmessi-aunque-dejo-un-mensaje-yo-no-utilizo-las-redes-sociales-para-discutir

Diario La Nación (26 de noviembre de 2019). La Justicia le prohibió a una mujer publicar injurias contra su expareja en Facebook. Recuperado de https://www.lanacion.com. ar/sociedad/la-justicia-le-prohibio-mujer-publicar-injurias-nid2309992

Diario La Nación (27 de noviembre de 2019). El BCRA volvió a encender la maquinita, tras 17 meses de abstinencia. Recuperado de https://www.lanacion.com.ar/economia/tras17-meses-abstinencia-volvio-financiamiento-monetario-nid2310337

Diario La Nación (28 de noviembre 2019). Tensión entre Facundo Arana y Fabián Mazzei tras la pelea Araceli-Suar. Recuperado de https://www.lanacion.com.ar/espectaculos/ personajes/tension-facundo-arana-fabian-mazzei-pelea-araceli-suar-nid2310630

Diario La Nación (29 de noviembre de 2019). Black Friday 2019: cómo comprar en Estados Unidos o conseguir las ofertas locales. Recuperado de https:/www.lanacion.com.ar/ tecnologia/black-friday-como-comprar-estados-unidos-conseguir-nid2310720

Diario Los Andes. (25 de junio de 2016). Martino: "Lo único que me preocupa es ganar el partido de mañana". Recuperado de http://www.losandes.com.ar/article/-ca2016-hoyultima-practica-antes-de-la-final-frente-a-chile

Diario Los Andes. (2 de julio de 2019). Ale Maglietti confirmó que un actor de "El Marginal" le escribió luego de su coqueteo. Recuperado de https://www.losandes.com.ar/alemaglietti-confirmo-que-un-actor-de-el-marginal-le-escribio-luego-de-su-coqueteo/

Diario Los Andes. (10 de julio de 2019a). Pella quedó eliminado de Wimbledón tras caer ante el español Bautista. Recuperado de https://www.losandes.com.ar/pella-quedoeliminado-de-wimbledon-tras-caer-contra-el-espanol-bautista/

Diario Los Andes. (10 de julio de 2019b). Aldo Rico: 'Ni el Presidente me puede impedir que desfile'. Recuperado de https://www.losandes.com.ar/aldo-rico-ni-el-presidente-mepuede-impedir-que-desfile/ 
Diario Los Andes. (10 de julio de 2019c). De no creer: influencer vende frascos con agua que usó para bañarse y se agotan en días. Recuperado de: https://www.losandes.com.ar/ de-no-creer-influencer-vende-frascos-con-agua-que-uso-para-banarse-y-se-agotanen-dias/

Diario UNO. (25 de junio de 2016). El campeón de la Copa América Centenario jugaría una final ante el de la Eurocopa. Recuperado de http://www.diariouno.com.ar/ ovacion/copa-america/el-campeon-la-copa-america-centenario-jugaria-una-final-ella-eurocopa-20160625-n970473

Diario UNO. (08 de febrero de 2018). José María Muscari: "Muchas veces ofrecen productos teatralmente muy endebles y con poco ensayo". Recuperado de https://www. diariouno.com.ar/cholunotas/jose-maria-muscari-muchas-veces-ofrecen-productosteatralmente-muy-endebles-y-con-poco-ensayo-02082018_B1MLV3X-0G

Diario UNO. (28 de noviembre de 2019a). Las pericias al chofer de la tragedia de la ruta 2. Recuperado de https://www.diariouno.com.ar/policiales/pericias-chofer--tragediaruta-2-11282019_ryIfXaT3S

Diario UNO. (28 de noviembre de 2019b). Dos radicales mendocinos se resisten a sellar un acuerdo en el Senado nacional. Recuperado de https://www.diariouno.com.ar/ politica/radicales-mendocinos-resisten-sellar-acuerdo-senado-nacional-11292019_ rlu2MJR3B

Fernández Lagunilla, M. y Anula Rebollo, A. (1995). Sintaxis y Cognición: Introducción al conocimiento, el procesamiento y los déficits sintácticos. Madrid: Síntesis.

Ferreres, H. (27 de noviembre de 2019). El costo de la vivienda en relación a los salarios. La Nación. Recuperado de https://www.lanacion.com.ar/opinion/el-costo-viviendarelacion-salarios-nid2310118

Flamenco García, L. (1999). Las construcciones concesivas y adversativas. En I. Bosque y V. Demonte (Dir.), Gramática descriptiva de la lengua española, Vol. 3 (pp. 3805-3878). Madrid: Espasa.

Gili Gaya, S. (2000 [1943]). Curso superior de sintaxis española. (15 impresión). Barcelona: Vox. Gutiérrez, M. (10 de julio de 2019). Yo, mis datos y el voraz capitalismo digital. Los Andes. Recuperado de https://www.losandes.com.ar/yo-mis-datos-y-el-voraz-capitalismodigital-por-miguel-angel-gutierrez/

Kovacci, O. (1992). El comentario gramatical. Teoría y Práctica. (Tomo II). Madrid: Arco Libros.

Lapesa, R. (1978). Sobre dos tipos de subordinación causal. En Estudios ofrecidos a E. Alarcos, Volumen 3 (pp. 173-205). Oviedo, España: Universidad de Oviedo.

López García, A. (2005). Gramática cognitiva para profesores de español L2. Madrid: Arco Libros.

Matthiessen, C. y Thompson, S. (1988). The Structure of Discourse and «Subordination». En J. Haiman y S. Thompson (Eds.), Clause Combining in Grammar and Discourse (p. 275-329). Ámsterdam-Filadelfia: John Benjamins.

Morón Usandivaras, M. (2012). Relaciones sintácticas en la zona adverbial: el caso de pues. Anuari de Filologia. Estudios de lingüística, (2), 1-15.

Morón Usandivaras, M. (2015). La expresión de la causa en el discurso alberdiano: De la anarquía y sus dos causas principales. (Tesis doctoral). Universidad de Buenos Aires. 
Narbona Jiménez, A. (1990). Las subordinadas impropias en español II. Málaga: Ágora.

Real Academia Española, Asociación de Academias de la Lengua Española (2010). Nueva gramática de la lengua española. Manual. Madrid: Espasa.

Rojo, G. (1978). Cláusulas y oraciones. Vigo: Universidad de Santiago de Compostela.

Traugott, E. y Dasher, R. (2002). Regularity in Semantic Change. Cambridge: Cambridge University Press.

Viceconte, A. (25 de junio de 2016). La Unión Europea presiona a Londres para que acelere la salida. Clarín. Recuperado de http://www.clarin.com/mundo/Union-Europeapresiona-Londres-acelere_0_1601839924.html 